\title{
Remarkable Weight Reduction for Low Carbohydrate Diet (LCD): Case Report
}

\author{
Hiroshi Bando $^{1 *}$, Koji Ebe ${ }^{2}$, Kazuki Sakamoto ${ }^{3}$, Tomoya Ogawa ${ }^{3}$, Masahiro Bando and Yoshikazu Yonei
}

${ }^{1}$ Tokushima University/ Medical Research, Tokushima, Japan

${ }^{2}$ Takao Hospital, Kyoto, Japan

${ }^{3}$ Sakamoto Hospital, Kagawa, Japan

${ }^{4}$ Department of Nutrition and Metabolism, Institute of Biomedical Sciences, Tokushima University Graduate School, Tokushima, Japan

${ }^{5}$ Anti-Aging Medical Research Center, Graduate School of Life and Medical Sciences, Doshisha University, Kyoto, Japan

\begin{abstract}
Background: There have been discussion for years concerning Calorie Restriction (CR) and low carbohydrate diet (LCD). As to LCD, we have reported clinical experience and research for glucose variability and ketone bodies.

Case and results: The patient was 41 yo man with type 2 diabetes mellitus (T2DM). His data includes height 186 $\mathrm{cm}$, BMI 31.2, fasting blood glucose $151 \mathrm{mg} / \mathrm{dL}, \mathrm{HbA} 1 \mathrm{c} 9.4 \%$. He was on super LCD diet with $12 \%$ of carbohydrate, and has continued aerobics exercise and muscle training. Average glucose level on day 2,4 and 10 was $161 \mathrm{mg} / \mathrm{dL}$, $117 \mathrm{mg} / \mathrm{dL}$ and $102 \mathrm{mg} / \mathrm{dL}$, respectively. Body weight decreased from $107 \mathrm{~kg}$ to $100 \mathrm{~kg}$ in 4 weeks. As ketone body, 3-hydroxybutyric acid (3-OHBA) was elevated to $2350 \mu \mathrm{mol} / \mathrm{L}(-85)$. Lipid profiles from day 2 to day 28 showed that Triglyceride 215 to 46 , HDL 32 to 44, LDL 89 to 93.
\end{abstract}

Discussion and conclusion: Authors have proposed 3 types of LCD so far, which are petit, standard and super, with $12 \%, 26 \%, 40 \%$ of carbohydrate ratio. Continuing super-LCD usually brings elevated ketone bodies and significant weight reduction. As for successful result, influenced factors would be application of super LCD, aerobics and anaerobic exercise, understanding and adequate continuation, adequate support of co-medicals.

Keywords: Low carbohydrate diet; Calorie restriction (CR); Type 2 diabetes mellitus (T2DM); Weight reduction, Petit-low carbohydrate diet (petit-LCD); Standard-low carbohydrate diet (standard-CD); Super-low carbohydrate diet (super-LCD); 3-hydroxybutyric acid (3OHBA)

Abbreviations: LCD: Low-Carbohydrate Diet; CR: Calorie Restriction; T2DM: Type 2 Diabetes Mellitus; VLCKD: Very LowCarbohydrate Ketogenic Diet; 3-OHBA: 3-hydroxybutyric acid

\section{Introduction}

There has been lots various discussion for long yeas concerning Calorie Restriction (CR) and low carbohydrate diet (LCD). Several studies have showed the efficacy of LCD, and its understanding and practice have been spread [1-5]. In Japan, the authors firstly reported the practice of LCD and developed clinical usefulness of LCD with patients with type 2 diabetes mellitus (T2DM) [6,7]. We also investigated the clinical significance of ketone bodies in fetus, placenta, newborn and pregnant mother [8].

In this study, case of T2DM with remarkable weight reduction would be presented and discussed.

\section{Case Report}

The patient was 41-year-old man whose occupation has been policeman. His lifestyle is hard and working until late every day with less holidays. He was diagnosed type 2 diabetes mellitus (T2DM) in another clinic, and was introduced to our DM clinic for further evaluation and treatment.

On physical examination, he showed $186 \mathrm{~cm}$ in height, $108 \mathrm{~kg}$ in weight, BMI 31.2 at admission. His vitals and consciousness are normal, and lung, heart, abdomen and neurological findings were unremarkable.

Laboratory data were as follows: fasting blood glucose $151 \mathrm{mg} / \mathrm{dL}$, postprandial glucose- $120 \mathrm{~min} 200 \mathrm{mg} / \mathrm{dl}$ on day 2 . HbAlc was $9.4 \%$, with GOT $25 \mathrm{IU} / \mathrm{mL}$, GPT $19 \mathrm{IU} / \mathrm{mL}$, r-GTP $18 \mathrm{IU} / \mathrm{mL}$, Alb $4.6 \mathrm{mg} / \mathrm{dL}$, $\mathrm{Hb} 16.7 \mathrm{~g} / \mathrm{dL}$.

\section{Diet Therapy for Super LCD}

The patient was given usual diabetes meal in day 1 and 2 , which is traditional Japanese formular diet for diabetes with $60 \%$ of carbohydrate, $1900 \mathrm{cal} /$ day. From day 3, he was given super LCD formular diet with $12 \%$ of carbohydrate which was originated by Dr. Ebe, Japan, one of the authors.

As to super LCD diet, calorie taken per day was calculated as follows: ideal weight $(\mathrm{kg})$ is $1.86 \times 1.86 \times 22=76.1 \mathrm{~kg}$, daily calorie taken per day is $76.1 \mathrm{~kg} \times 25 \mathrm{kcal} / \mathrm{kg} / \mathrm{day}=1900 \mathrm{kcal} /$ day. As super LCD diet contains $12 \%$ of carbohydrate, he took 228 calories of carbohydrate per day. As 1 gram of carbohydrate has $4 \mathrm{kcal}$, then carbohydrate intake per day is $228 \mathrm{~g} / 4=57$ grams per day.

Japanese style meal has always includes one bowl of rice, but super LCD meal does not include rice, bread or noodles. One example of lunch was shown in Figure 1, which is Japanese style Sukiyaki with 26 $\mathrm{g}$ of carbohydrate.

\section{Exercise Therapy}

The patient was formerly a judo athlete when he was college student, then he is accustomed to train himself. During admission, he went out for a walk with large stride length 1 hour in the morning and 1 hour in

*Corresponding author: Hiroshi Bando, Tokushima University/ Medical Research, Tokushima, Japan, Tel: +81-90-3187-2485; Email: pianomed@bronze.ocn.ne.jp

Received: September 20, 2017; Accepted: October 11, 2017; Published October 15, 2017

Citation: Bando H, Ebe K, Sakamoto K, Ogawa T, Bando M, et al. (2017) Remarkable Weight Reduction for Low Carbohydrate Diet (LCD): Case Report. Diabetes Case Rep 2: 130. doi: 10.4172/2572-5629.1000130

Copyright: $\odot 2017$ Bando $\mathrm{H}$, et al. This is an open-access article distributed under the terms of the Creative Commons Attribution License, which permits unrestricted use, distribution, and reproduction in any medium, provided the original author and source are credited. 
Citation: Bando H, Ebe K, Sakamoto K, Ogawa T, Bando M, et al. (2017) Remarkable Weight Reduction for Low Carbohydrate Diet (LCD): Case Report. Diabetes Case Rep 2: 130. doi: 10.4172/2572-5629.1000130

the afternoon. Moreover, He has continued muscle training on trunk and extremities for more than 1 hour in his admitted room.

He continued these exercises spontaneously by his own decision, and he usually sweated well with comfortable feeling.

\section{Changes of Biomarkers}

Daily profile of blood glucose was investigated on day 2, 4 and 10 (Figure 2). Glucose profile revealed remarkable decrease.

To check postprandial glucose-120 minutes and body weight once per week, both value showed remarkable decrease (Figure 3). Body weight decreased from $107 \mathrm{~kg}$ to $100 \mathrm{~kg}$ in 4 weeks.

Urinary C-peptide excretion on day 2 (CR) and 3 (LCD) was 55.9 $\mathrm{mg} /$ day and $45.4 \mathrm{mg} /$ day, respectively, with normal range $23-155 \mathrm{mg} /$ day. Lipid profiles from day 2 to day 28 showed that Triglyceride 215 to 46, HDL 32 to 44, LDL 89 to 93.

The fracture of ketone bodies in blood was measured on day 10 , which were total ketone bodies $3055 \mu \mathrm{mol} / \mathrm{L}(-131)$, Acetoacetate 705 $\mu \mathrm{mol} / \mathrm{L}(-55)$ and 3-hydroxybutyric acid (3-OHBA) $2350 \mu \mathrm{mol} / \mathrm{L}(-85)$. 3-OHBA has the activity for ketone body.

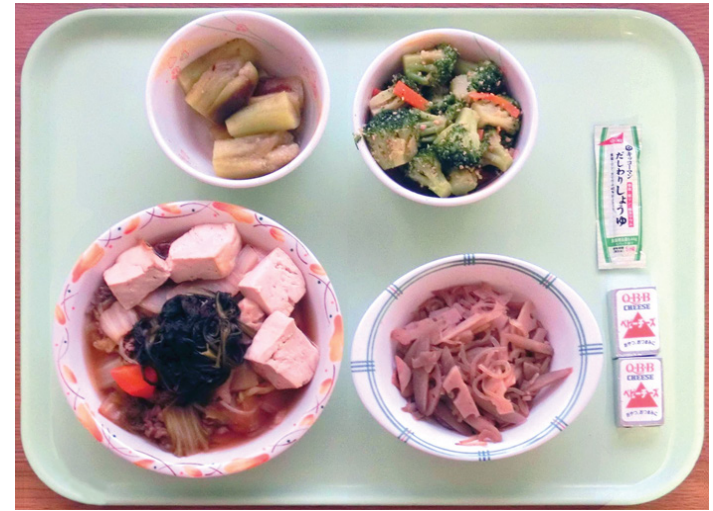

In this meal, the kinds of foodstuff and carbohydrate dose are as follows:

- Japanese style Sukiyaki with beef, tofu, egg, jelly, onion, mushroom, edible chrysanthemum, Japanese leek, other vegetable and sukiyaki soup $12 \mathrm{~g}$, lotus root and jelly $6.7 \mathrm{~g}$,

- 2 pieces of process cheese $0.4 \mathrm{~g}$ eggplant $3.6 \mathrm{~g}$,

broccoli and carrot with sesame $3 \mathrm{~g}$

soy sauce $(5 \mathrm{~g}) 0.3 \mathrm{~g}$

Sum total from a) to $\mathrm{f}$ ) is $26 \mathrm{~g}$ of carbohydrate of this meal.

Figure 1: Japanese style Sukiyaki for lunch as formular diet of super LCD.

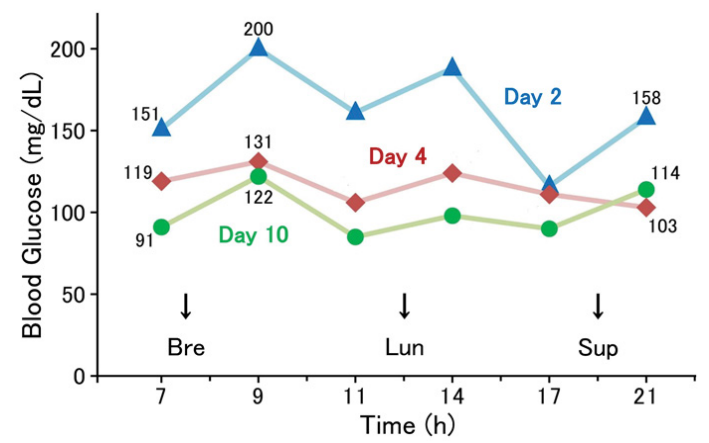

Figure 2: Daily profile of blood glucose on day 2, 4 and 10 Glucose profile showed remarkable decrease from day 2, 4 to 10 .

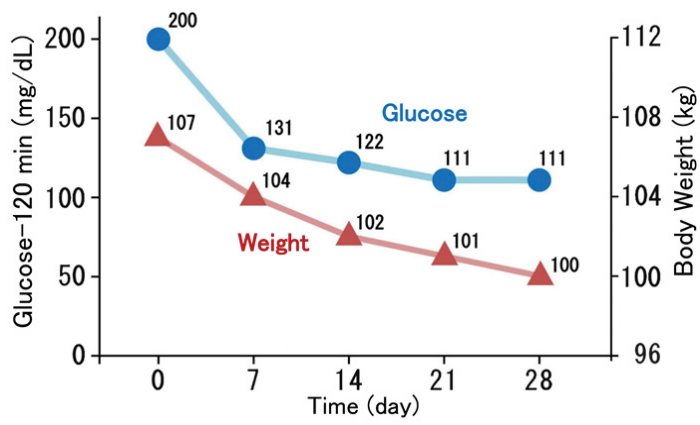

Figure 3: Changes of weight and postprandial glucose-120 min. for 4 weeks. Body weight showed remarkable decrease, with decrease of postprandial glucose-120 min

\section{Discussion}

After LCD was firstly initiated $[9,10]$, authors have started and continued LCD movement in Japan for years medically and socially, and we have proposed 3 patterns of LCD $[6,7,11,12]$. There are 1) superLCD: strictly limited in 3 meals, 2) standard-LCD: limited in 2 meals a day, 3) petit-LCD: limited in 1 meal a day. The ratio of carbohydrate is $12 \%, 26 \%, 40 \%$, respectively. On contrast, traditional formula diet for diabetes in Japan was $50-60 \%$.

In our previous study, clinical experience for LCD with 2699 cases are reported [13]. Weight reduction of more than $10 \%$ was observed in $25.6 \%$ of subjects, and more than $2.5 \%$ was observed in $78.8 \%$ of subjects, indicating the efficacy of LCD.

There is a useful marker indicating high blood glucose and mean amplitude of glycemic excursions (MAGE), which is Morbus (M) value. Authors have investigated $\mathrm{M}$ value and related markers, and clarified the usefulness of $\mathrm{M}$ value $[14,15]$.

In this study, daily profile of blood glucose on day 2,4 and 10 indicated remarkable improvement of diabetic status. Average glucose on 2,4 and 10 was $161.1 \pm 27.2 \mathrm{mg} / \mathrm{dL}, 117.1 \pm 10.7 \mathrm{mg} / \mathrm{dL}$ and $101.7 \pm$ $14.2 \mathrm{mg} / \mathrm{dL}$, respectively.

When we calculate Morbus (M) value on day 2,4 and 10, the result was $28.6,2.0$ and 9.6, respectively. The reason why $M$ value increased from day 4 to day 10 is that Morbus (M) value becomes minimum when glucose level in average is around $120 \mathrm{mg} / \mathrm{dL}$ and the fluctuation of glucose becomes less. The reason is that the formula of $\mathrm{M}$ value comes from $10 \times$ LOG (glucose value/120) and its cube data. Then glucose profile on day 4 seems to be ideal in the light of $M$ value.

Nutrition diet has been classified into several categories [16]. They are 1) Very low-carbohydrate ketogenic diet (VLCKD): Carbohydrate, $20-50 \mathrm{~g} / \mathrm{d}$ or $<10 \%$ of the $2000 \mathrm{kcal} / \mathrm{d}$ diet, 2) Low-carbohydrate diet: $<130$ g/d or $<26 \%$ total energy, 3) Moderate-Carbohydrate Diet: $26 \%-$ $45 \%$, 4) High-Carbohydrate Diet: $>45 \%$ [16].

Super-LCD is one of VLCKD, and contains $12 \%$ of carbohydrate. Continuing Super-LCD usually makes the patient elevated ketone bodies and significant weight reduction [13,15,16]. Continuing ketogenic diet seems to be necessary to obtain enough weight reduction [17-19]. Furthermore, the ratio of carbohydrate in LCD showed correlation with the degree of weight reduction [20].

\section{Conclusion}

Current study revealed that the case showed remarkable decrease of 
Citation: Bando H, Ebe K, Sakamoto K, Ogawa T, Bando M, et al. (2017) Remarkable Weight Reduction for Low Carbohydrate Diet (LCD): Case Report. Diabetes Case Rep 2: 130. doi: 10.4172/2572-5629.1000130

Page 3 of 3

glucose and body weight in 4 weeks. We speculate the influenced related factors, which are 1) application of LCD rather than CR, 2) especially super LCD with $12 \%$ of carbohydrate, 3 ) enough exercise both aerobics and anaerobic movement, 4) right understanding and continuation mentally and psychologically, 5) adequate support of co-medicals such nurse and dietician.

\section{Acknowledgement}

The authors would like to thank the patients and staffs for their cooperation and support. The authors declare that they have no conflicts of interest.

\section{References}

1. Shai I, Schwarzfuchs D, Henkin Y, Shahar DR, Witkow S, et al. (2008) Weight loss with a low-carbohydrate, mediterranean, or low-fat diet. N Engl J Med 359: 229-241.

2. Schwarzfuchs D, Golan R, Shai I (2012) Four-year follow-up after two-year dietary interventions. N Engl J Med 367: 1373-1374.

3. Mansoor N, Vinknes KJ, Veierød MB, Retterstøl K (2016) Effects of lowcarbohydrate diets vs. low-fat diets on body weight and cardiovascular risk factors: a meta-analysis of randomised controlled trials. Br J Nutr 14; 115: 466479 .

4. Meng Y, Bai H, Wang S, Li Z, Wang Q, et al. (2017) Efficacy of low carbohydrate diet for type 2 diabetes mellitus management: A systematic review and metaanalysis of randomized controlled trials. Diabetes Res Clin Pract 131: 124-131.

5. Namazi N, Larijani B, Azadbakht L (2017) Low-carbohydrate-diet score and its association with the risk of diabetes: A systematic review and meta-analysis of cohort studies. Horm Metab Res 49: 565-571.

6. Ebe K, Ebe Y, Yokota S (2004) Low carbohydrate diet (LCD) treated for three cases as diabetic diet therapy. Kyoto Medical Asso J 51: 125-129.

7. Bando H, Nakamura $T$ (2008) Carbo-count therapy and low carbohydrate die (LCD). Endo Res Meta 90: 3105-3111.

8. Muneta T, Kawaguchi E, Nagai Y, Matsumoto M, Ebe K (2016) Ketone body elevation in placenta, umbilical cord, newborn and mother in normal delivery. Glycative Stress Res 3: 133-140.
9. Atkins R (1998) Dr. Atkins' new diet revolution, Rev edn. Avon books, New York, USA.

10. Bernstein RK (2007) Dr. Bernstein's diabetes solution: The complete guide to achieving normal blood sugars. Little, Brown, New York, USA

11. Bando H, Ebe K, Muneta T, Bando M, Yonei $Y$ (2017) Clinical effect of low carbohydrate diet (LCD): case report. Diabetes Case Rep 2: 124.

12. Ebe $K$ (2017) The revolution of low carbohydrate diet (LCD) -the paradigm shift of health, food, medicine and society- Oriental Economy Publishing, UK.

13. Bando $H$, Ebe $K$, Nakamura T, Bando M, Yonei Y (2016) Low carbohydrate diet (LCD): Long and short-term effects and hyperketonemia. Glycative Stress Res 3 193-204.

14. Ebe K, Bando H, Muneta T, Bando M, Yonei Y (2017) Effect of low carbohydrate diet (LCD) for diabetic patients with hypertriglycemia. Endocrinol Metab 1(1): 104

15. Bando H, Ebe K, Muneta T, Bando M, Yonei Y (2017) Effect of low carbohydrate diet on type 2 diabetic patients and usefulness of M-value. Diabetes Res Open J 3(1): 9-16.

16. Feinman RD, Pogozelski WK, Astrup A, Bernstein RK, Fine EJ, et al. (2015) Dietary carbohydrate restriction as the first approach in diabetes management: Critical review and evidence base. Nutrition 31: 1-13.

17. Saslow LR, Kim S, Daubenmier JJ, Moskowitz JT, Phinney SD, et al. (2014) A randomized pilot trial of a moderate carbohydrate die compared to a very low carbohydrate diet in overweight or obese individuals with type 2 diabetes mellitus or prediabetes. Plos one 9: e91027.

18. Hussain TA, Mathew TC, Dashti AA, Asfar S, Al-Zaid N (2012) Effect of low-calorie versus low-carbohydrate ketogenic diet in type 2 diabetes. Nutrition 28: 10161021.

19. Watanabe S, Hirakawa A, Utada I, Aoe S, Moriyama S, et al. (2017) Ketone body production and excretion during wellness fasting. Diabetes Res Open $\mathrm{J}$ 3: $1-8$.

20. Snorgaard O, Poulsen GM, Andersen HK, Astrup A (2017) Systematic review and meta-analysis of dietary carbohydrate restriction in patients with type 2 diabetes. BMJ Open Diabetes Res Care 5: e000354 